\title{
The Characteristics and Motivations Behind Female Prison Sex
}

\author{
Christopher Hensley \\ Richard Tewksbury \\ Mary Koscheski
}

\begin{abstract}
Research on the topic of consensual same-sex sexual activities within female prisons has been sparse in sociological and correctional literature. The purpose of the present study was to examine the characteristics and motivations which affect a female inmate's decision to engage in same-sex sexual activity. The most significant and salient variables associated with the same-sex sexual activity among female inmates were age and amount of time served. Younger inmates and those who had served longer periods of time incarcerated were identified as more likely than older inmates and women who have served shorter periods of time to engage in homosexual activity. Race and religion also had a significant effect on selected same-sex sexual behavior in the female correctional facility. The present study finds equal, but limited support for both the deprivation and importation models. [Article copies available for a fee from The Haworth Document Delivery Service: 1-800-HAWORTH. E-mail address: <getinfo@haworthpressinc.com> Website: $<$ http://www.HaworthPress.com> (c) 2002 by The Haworth Press, Inc. All rights reserved.]
\end{abstract}

Christopher Hensley is Director, Institute for Correctional Research and Training and Assistant Professor, Department of Sociology, Social Work, and Criminology, Morehead State University, 114 Rader Hall, Morehead, KY 40351.

Richard Tewksbury is Professor, Department of Justice Administration, University of Louisville, Department of Justice Administration, Louisville, KY 40292.

Mary Koscheski is Graduate Research Assistant, Department of Sociology, Social Work, and Criminology, Morehead State University, 114 Rader Hall, Morehead, KY 40351 .

Women \& Criminal Justice, Vol. 13(2/3) 2002

(C) 2002 by The Haworth Press, Inc. All rights reserved. 
KEYWORDS. Female prison sex, importation model, deprivation model, pseudo-families, correctional policy regarding prison sex

Although research on female prison sexuality has been conducted for the past eighty years, the topic has received only scattered attention among penologists. The subject most frequently addressed in women's prison sex studies is the role of pseudo-families within institutional cultures. Few studies have addressed the characteristics of female inmates who engage in same-sex sexual activity and the motivations behind their decision to participate in this behavior.

The two distinct, yet interrelated (see Eigenberg, 1992), perspectives that are commonly addressed in the study of sexual behavior of females in prison are the deprivation and importation models (Greer, 2000; Owen, 1998; Propper, 1982, 1981, 1978, 1976; Nelson, 1974; Heffernan, 1972; Kassebaum, 1972; Giallombardo, 1966; Ward and Kassebaum, 1965; Halleck and Hersko, 1962). The aspects of the deprivation model were originally outlined by Sykes (1958) as being the forfeiture of liberty, withholding of goods and services, denial of heterosexual relationships, loss of autonomy, the sacrifice of security, boredom, lack of privacy, and forced association. These "pains of imprisonment" are experienced differently by men and women in correctional settings. While both sexes suffer loss of self-image, routinization of daily life, restrictions and punishments for violation of rules, and segregation from the outside world, women cite companionship and separation from their children/families as the major "pains of imprisonment" (Pollock, 1997; Kassebaum, 1972; Giallombardo, 1966). Thus, the occurrence, formation, and inclusion into a "make-believe" family has been theorized to fulfill some of these women's loss of identity and emotional needs during incarceration. Homosexual relationships, therefore, are seen to evolve from these psychological and physiological desires. These include, but are not limited to, feeling wanted or needed, being appreciated, feeling affection for and by another, emotional ties, economic fears, sexual intimacy, and group/peer acceptance (Owen, 1998; Pollock, 1997; Propper, 1982; Ward and Kassebaum, 1965).

In contrast, the importation model argues that patterns of behavior, social and cultural experiences, race, social class, previous incarceration, and membership in various groups predispose the characteristics, actions, and adherence to the subculture values of an individual during incarceration (Greer, 2000; Owen, 1998; Pollock, 1997; Propper, 1981; Nelson, 1974; Heffernan, 1972; Ward and Kassebaum, 1965; Irwin and 
Cressey,1962). Sex roles, expectations, needs, and values from the outside world affect one's behavior in prison.

The emotional and sexual needs that women import into prison differ greatly from individual to individual. The membership roles within pseudo-families are seen as enabling many women to function in the same capacity that they had on the outside (wife, mother, daughter, sister, etc.). Emotional needs of acceptance, nurturing, and affiliation with others are shared through the kinship network. Family values, ideas, norms, and traditions from their "outside" families may be incorporated into their "inside" families. The "inside" family can also be used as a sounding board and receptacle for problems occurring with the members of the "outside families." Younger members (daughter or sisters) often find cohesiveness, emotional ties, and stability which was lacking in their natural families (Pollock, 1997; Propper, 1981; Giallombardo, 1966; Ward and Kassebaum, 1965). When considering homosexuality as an imported commodity, it is assumed that those who engage in homosexual behavior before incarceration continue to do so during incarceration (Propper, 1981). Sexuality, then, is just one behavior/value that follows an inmate from the street to prison.

\section{LITERATURE REVIEW}

Research on sex in female correctional facilities has been sporadic and provided only an incomplete understanding of the incidence, structure, and dynamics of sexual relationships among female inmates. The topics most frequently addressed in this literature focus primarily on the formation of pseudo-families and if and why homosexuality emerges once a female is incarcerated. Few studies have examined the number of women who engage in homosexual behavior prior to and during incarceration. The purpose of this study is to understand the motivations, dynamics, incidence, and characteristics of women engaged in consensual same-sex sexual behavior while incarcerated.

The initial sex studies conducted on incarcerated females (Selling, 1931; Ford, 1929; Otis, 1913) scrutinized the "unnatural relationship" between black and white females in reform schools and institutions for delinquent girls. Otis (1913), for example, argued that same-race homosexuality between females was a "difficult issue" to address. However, homosexuality between white and black females was seen as a "perversion not commonly noted" (p. 113). Both black and white girls often entered into these relationships for fun and entertainment. For many, 
however, it became a serious enthrallment that evolved into a sexual relationship. Otis stated, "the difference in color, in this case, takes the place of difference in sex, and ardent love-affairs arise between white and colored girls in schools where both are housed together" (p. 113).

Ford's (1929) study found similar results with the added commodity that many of the girls did not limit themselves to one partner. This study suggested that not only were these girls guilty of infidelity, but also that they assumed both dominant and submissive roles in respect to the same behavior. Selling (1931) expanded the focus and examined the pseudofamily alliances which developed in female juvenile institutions. These alliances evolved as a psychological, non-pathological substitute family because of the emotional disassociation from their own families. It is regrettable that neither Otis, Ford, nor Selling used any type of statistical analysis to corroborate their findings. In addition, these early researchers did not provide a clear conceptual or operational definition of "sexual" acts. Most of their findings on the type and amount of female homosexuality within juvenile facilities came from their own perceptions and from staff estimates.

Research-based methodologies for examining girls and women's experiences with prison sex first appeared in 1962. In 1962, Halleck and Hersko gathered data on 57 girls' sexual behavior inside a juvenile institution by administering a 73-item written biographical inventory. The results indicated that a large majority of the girls became involved in homosexual relationships, with a wide range of types of relationships. Differing levels of emotional involvement and sexual intimacy were identified across individuals and relationships. For example, 69\% of the females reported they had engaged in "girl stuff" (dancing, holding hands, kissing, and going together). However, only five percent of the girls reported that they had stimulated another girl's genitalia, while seven percent had permitted another girl to stimulate hers. The majority of these "relationships" were found to be "short-lived and superficial" (p. 913).

Ward and Kassebaum (1965) studied female inmates' sexual behaviors at the California Institution for Women in Frontera, California. Their definition of homosexuality included women engaging in "kissing and fondling of the breasts, manual or oral stimulation of the genitalia and intercourse between two women" (p. 80). Prison records identified $19 \%$ of the prison population as homosexual. This finding came from "disciplinary reports, reports of community investigations by probation officers, case materials from other prisoners, reports by psychiatrists and psychologists, and admission by inmates to custodial 
or social service personnel" (90). Results of anonymous surveys and interviews with both staff $(\mathrm{N}=64)$ and inmates $(\mathrm{N}=293)$, however, estimated that between $30 \%$ and $75 \%$ of the female inmates had sexual affairs while in prison. Ward and Kassebaum estimated that approximately fifty percent of the women had engaged in "some form of overt sexual experience at least sometime during their sentence" (Kassebaum, 1972, p. 43).

Giallombardo's (1966) research in the West Virginia Women's Federal Reformatory (Alderson) continued to focus on relationships and the construction of "families" for emotional support. By focusing on the intergroup and interpersonal relationships that developed among the female inmates, the sexual aspects of these relations were secondary in significance. The relationships female inmates constructed were seen as important for addressing the women's social, psychological, and physiological needs. Pseudo-families (or kinship networks) were the intergroup alliances which were created as a "proxy" family for the women. Within these kinships, roles were constructed consistent with the behavior that an inmate displayed (daddy, mommy, brother, etc.). In relation to other inmates in the network, the prison "family" performed all the functions normally attributed to the biological family, except procreation. These kinship ties usually lasted throughout the inmate's sentence, despite the fact that the individual's role could change within a given kinship. When sexual relationships occurred within the "family," it was only between the daddy and mommy.

Although not her primary focus, Giallombardo did address sexualized relationships between inmates. She observed that a vast majority of the inmates adjusted to prison life by forming alliances with a compatible partner as a marriage unit. The inmates maintained that "to engage in homosexuality as duplication of the outside world, makes times go by faster and (furthermore) that no one can do time alone" (Giallombardo:1966, p.136). These relationships were established on a voluntary basis with no evidence of any physical or psychological coercion, as is often the case in male prisons. The women's subculture recognized these dyadic relationships as legitimate marriages that provided inmates with companionship, a sense of belonging, a demonstration of affection and love from another, and a confidant. Somewhat ironically, most of these alliances were short-lived; most "marriages" lasted less than three months.

Giallombardo's (1966) estimates of the number of inmates involved in same-sex relationships varied according to those interviewed. Inmates placed the number between $90 \%$ to $95 \%$, while correctional offi- 
cers estimated the figures between $50-75 \%$. Only $5 \%$ of the inmate population, however, had engaged in homosexual behavior prior to incarceration. Rather clearly, then, homosexuality was a result of institutional culture and/or the deprivations of life in prison.

The pseudo-family approach to understanding the culture, especially the sexual culture, of women's prisons remained dominant in research and theory well into the 1970s. Two significant studies in the 1970s, Heffernan's (1972) research in the Women's Reformatory of the District of Columbia and Propper's $(1982,1981,1978,1976)$ work in female juvenile institutions maintained the analytic emphasis on the construction of pseudo-families. As social constructs, pseudo-families provided women with emotional/psychological support for coping with the stresses of incarceration, assistance with daily living tasks (via the delegation of tasks among family members based on kinship roles), and opportunities for emotional and sexual intimacy. The importance of the non-sexual aspects of pseudo-families can be seen in the fact that Heffernan's (1972) interviews with 100 adult women revealed that approximately one-half of all women were involved in a family network, while Propper's work with juveniles revealed only about one in seven girls were so involved. Direct evidence of sexual activities is not available from either researcher, largely due to the reluctance of inmates to discuss rule violations.

Yet not all researchers have found a high rate of sexual relationships between female inmates. Tittle (1972) reported that only 14\% of the female inmates of a narcotic hospital were involved in homosexual behavior with another female since incarceration. Similar to the structure of the institutions studied by Propper, the patients in Tittle's narcotics hospital were institutionalized for relatively short periods of time. As such, the effects of deprivation are less likely to be significantly experienced by the women, and coping mechanisms may be less likely to be activated.

The presumed sexual aspect of pseudo-family relationships is seriously drawn into question in the late 1970s and 1980s with Propper's revision of her original thesis. Rather than simply assuming that women in relationships described with terms suggesting a sexual partnership (i.e., husband/wife) were in fact sexual liaisons, Propper explored their dynamics. Her more recent studies revealed most pseudo-kin relationships were not husband-wife, but degrees of relativity, and most often non-sexual. The most significant factor identifying the female inmates who became involved in sexual relations with other inmates was pre-prison sexual activities. 
Instead of presenting same-sex relationships (either sexual or otherwise) as a response to the deprivations of incarceration, the data emerging in the late 1970s and 1980s suggested that sexual identities and activities are fairly stable across pre-prison and in-prison experiences. In large part this change in thinking and in research foci was an outgrowth of changing conceptions and definitions of homosexuality. Not until the mid-1970s was homosexuality removed from the "official" listing of mental illnesses (American Psychiatric Association, 1994). Once homosexuality was no longer officially defined as a "disease," researchers began to alter their approaches to understanding the dynamics and prevalence of such behaviors. Researchers (Propper, 1982, 1981, 1978, 1976; Hopper, 1980) began to see prison homosexuality as merely an extension of pre-prison identities and behaviors. Consequently, the theoretical focus moved from a deprivation model (Sykes, 1958) to an importation model (Irwin and Cressey, 1962). Homosexuality came to be viewed as a (somewhat) acceptable form of social behavior that is self-reinforcing. In simplest terms women who found same-sex sexual activities satisfying before coming to prison could be expected to continue engaging in such activities during incarceration (Propper, 1981).

The change in theoretical orientation and definitions of homosexuality by the mental health community and subsequently by other "official" institutions and agencies opened the door to researchers documenting high rates of same-sex sexual activities among female prison inmates. Nelson (1974), for example, found that roughly 55\% of the black female inmates and $37 \%$ of the white inmates (of the 119 respondents) considered themselves to be homosexual while incarcerated. Hopper (1980), based on her face-to-face interviews with 176 female inmates in the Florida Correctional Institution, reported that $49 \%$ of the female inmates of the prison had engaged in homosexual activities while incarcerated $(75 \%$ of these women also reported pre-prison homosexual experiences). Contrary to Nelson's (1974) report that black women were more likely to be involved in same-sex relationships while incarcerated, Hopper (1980) reported no statistically significant differences between blacks' and whites' reporting of participation in homosexual behavior. It was found that "a greater proportion of younger inmates (age group 21-25) engaged in homosexual activities than the total in any of the remaining groups" (Hopper, 1980, p. 64).

The most recent investigations of incarcerated women's sexual have continued with an emphasis on identifying and documenting the contributions of pseudo-families, as well as expanding the focus to issues of sexuality in general. However, rather than simply looking for the pres- 
ence of relationships paralleling traditional extended family kinship relations, contemporary researchers (Greer, 2000; Owen, 1998) have expanded their examinations to assessments of friendships and support systems.

What this newest research suggests is the impact of interpersonal relationships, especially those of a kinship-like nature, has greatly dissipated. Based on 294 face-to-face interviews with female inmates, Owen (1998) found family-like relationships did exist in the Central California Women's Correctional Facility, but that they were typically shortlived and most common among women newer to the prison. As length of incarceration increased, reliance on others for support and the presence of supportive relationships with other inmates decreased significantly.

Greer's (2000) face-to-face interviews with 35 female inmates in a Midwestern women's prison strongly counters the presence of pseudofamilies and interpersonal supportive relationships. Rather than seeing incarcerated women working together to manage the stresses of incarceration, this newest research results suggest that women's institutions are becoming like men's prisons, where mistrust of others, manipulation, loneliness and a general lack of emotional bonding among inmates defines the culture (Greer, 2000).

The lack of emotional bonding and close social relationships does not mean that today's female inmates are not sexually active, however. Both Owen (1998) and Greer (2000) report at least one-third of the women in their prisons are sexually active with other inmates. Although the general culture of women's prisons has changed-as have many of the common characteristics of incarcerated women-women continue to be sexually active during incarceration. Our traditional explanations for prison sexuality are, however, drawn into question by these changes. Can the deprivation and/or the importation model(s) offer adequate explanations for female prison inmates' sexual activities and relationships? This is the question at the heart of this study.

\section{METHODS}

\section{Subjects}

In March 2000, all inmates housed in a Southern correctional facility for women were requested to participate in the current study. Inmates were assembled in the main area of their respective units by correctional staff in order that the researchers could explain the contents of the sur- 
veys. The lead researcher and a graduate assistant then distributed self-administered questionnaires to each inmate. Inmates were told it would take approximately 30 minutes to complete the 46-item questionnaire. In addition, they were informed of their anonymity and the confidentiality of their participation in the project. No incentives were given for completion of the survey. Inmates were asked to return their completed questionnaires in a stamped, self-addressed envelope within two weeks of distribution. Of the 643 females incarcerated at that time, a total of 245 agreed to participate in the study, yielding a response rate of $38 \%$.

Table 1 displays the characteristics of the prison population and the sample. A comparison of the prison population and the study group reveals some slight differences. For example, blacks and inmates in medium security are under-represented in the sample. Inmates describing their race as other and maximum security inmates were over-represented in the sample.

\section{Measures}

Inmates were asked four questions concerning their consensual samesex behavior while incarcerated. Inmates were asked: (1) Have you kissed another inmate in a sexual manner since being incarcerated?; (2) Have you touched another inmate in a sexual manner since being incar-

TABLE 1. Population and Sample Characteristics

\begin{tabular}{|c|c|c|c|c|}
\hline \multirow[b]{2}{*}{ Characteristic } & \multicolumn{2}{|c|}{$\begin{array}{c}\text { Prison } \\
\text { Population }\end{array}$} & \multicolumn{2}{|c|}{ Sample } \\
\hline & $\mathrm{N}$ & Percent & $\mathrm{n}$ & Percent \\
\hline \multicolumn{5}{|l|}{ Race: } \\
\hline White & 394 & $61.3 \%$ & 150 & $61.2 \%$ \\
\hline Black & 247 & 38.4 & 82 & 33.5 \\
\hline Other & 02 & 0.3 & 11 & 4.4 \\
\hline \multicolumn{5}{|l|}{ Security Level: } \\
\hline Minimum & 241 & $37.5 \%$ & 92 & $40.2 \%$ \\
\hline Medium & 393 & 61.1 & 121 & 52.8 \\
\hline Maximum & 09 & 1.4 & 16 & 7.0 \\
\hline Average Age: & \multicolumn{2}{|c|}{35.0 years } & \multicolumn{2}{|c|}{34.4 years } \\
\hline
\end{tabular}


cerated?; (3) Have you received oral sex from another inmate since being incarcerated?; and (4) Have you performed oral sex on another inmate since being incarcerated? These items were used to construct a variable of female inmates who participated in homosexual behavior while incarcerated. Responses were dichotomized so that negative responses were coded as zero and affirmative responses received a score of one. All of these items served as dependent variables.

Demographic characteristics (age and race) were recorded for the study group. Data were also collected on religion (Protestant v. NonProtestant), education (high school or less v. some college or more), amount of time served (less than 1 year, 1-5 years, 5-10 years, and more than 10 years), type of offense committed, and security level.

\section{RESULTS}

Of the 245 female inmates who responded to the questionnaire, when asked about their sexual orientation during incarceration, only $55 \%$ reported they identified being "straight" with an additional $31 \%$ reporting a bisexual identity and $13.5 \%$ reporting a lesbian identity. Table 2 displays the proportion of the sample reporting participation in homosexual behavior, including the four forms of same-sex sexual behaviors during incarceration. Over $45 \%$ of the sample reported engaging in any form of same-sex sexual behavior during incarceration.

Because the dependent variables are dichotomous, a series of logistic regression analyses were performed to test if the predictor variables had an effect on the dependent variables. The most salient variables in the models predicting consensual same-sex sexual activity while incarcerated were age and amount of time served. Both variables are statistically significant predictors of all five dependent variables (participating in same-sex sexual activities, kissing, touching, receiving, and performing oral sex). Age is the variable that shows the greatest influence on female inmates' same-sex sexual behavior. Women under the age of 34 are more likely to engage in all five varieties of behavior. The length of time that a woman has served in prison is also a statistically significant predictor of all five dependent variables. Women who have served longer periods of time incarcerated are more likely than women who have served shorter periods of time to engage in same-sex sexual activities with another inmate. The race variable, however, is a statistically significant predictor of only two forms of same-sex sexual behavior: touching another inmate in a sexual way and receiving oral sex. Non-white 
TABLE 2. Inmates Engaging in Homosexual Activities During Incarceration

\begin{tabular}{lc}
\hline & $\begin{array}{c}\text { During } \\
\text { Incarceration }\end{array}$ \\
\hline Participation in Homosexual Behavior & $45.5 \%$ \\
Kissed Another Female & $43.7 \%$ \\
Touched Another Female & $40.0 \%$ \\
Received Oral Sex by Another Female & $30.6 \%$ \\
Performed Oral Sex on Another Female & $26.6 \%$ \\
\hline
\end{tabular}

women are more likely to touch another woman in a sexual manner and to receive oral sex from another female inmate. The only other statistically significant variable in the equation is religion. Women who report a Non-Protestant religious affiliation are significantly more likely to have performed oral sex on another inmate. As shown in Table 3, between one-fourth and one-third of the total variance in the analyses was explained by the predictor variables.

\section{DISCUSSION}

Unfortunately, female prison sex studies have not explored factors affecting an inmate's decision to engage in homosexual activity. As previously mentioned, the few studies on female prison sexuality that were conducted in the last two decades found more support for the importation model. The present study, however, finds equal, but limited support for both the deprivation and importation models. In the present study four factors, race, amount of time served, religion, and age, significantly affected an inmate's decision to engage in same-sex sexual activity. Race was found to significantly affect an inmate's decision to engage in same-sex sexual behavior. Non-white women (82 of the 93 non-white female inmates were black) in our sample were more likely to engage in same-sex sexual behavior than white women. This finding supports Nelson's (1974) study on female prison sexuality. Black women in prison, according to Nelson, are more able to openly express themselves sexually. It should be noted that our analysis examines white v. non-white differences not white v. black differences. Furthermore, our analysis notes an over-representation of "other races" and under-representation of black women. Because this is a tentative finding at 
TABLE 3. Summary of Logistic Regression Beta Weights $(n=225)$

\begin{tabular}{|c|c|c|c|c|c|}
\hline & $\begin{array}{c}\text { Participation in } \\
\text { Homosexual } \\
\text { Behavior }\end{array}$ & Kissing & Touching & $\begin{array}{l}\text { Received } \\
\text { Oral Sex }\end{array}$ & $\begin{array}{l}\text { Performed } \\
\text { Oral Sex }\end{array}$ \\
\hline Age & $-1.43^{*}$ & $-1.30^{*}$ & $-1.44^{*}$ & $-1.28^{*}$ & $-1.06^{*}$ \\
\hline Race & -0.54 & -0.56 & $-0.88^{*}$ & $-1.09^{*}$ & -0.69 \\
\hline Religion & 0.60 & 0.40 & 0.51 & 0.39 & $1.01^{*}$ \\
\hline Education & 0.39 & 0.35 & 0.21 & 0.49 & 0.56 \\
\hline Amount of Time Served & $0.60^{*}$ & $0.61^{*}$ & $0.78^{*}$ & $0.84^{*}$ & $0.59^{*}$ \\
\hline Type of Offense & -0.44 & -0.51 & -0.66 & -0.73 & -0.66 \\
\hline Security Level & 0.50 & 0.53 & 0.39 & 0.35 & 0.49 \\
\hline Pseudo $\mathrm{R}^{2}$ & 0.27 & 0.26 & 0.31 & 0.31 & 0.27 \\
\hline
\end{tabular}

best, future research should explore racial differences and sexual behaviors by expanding the number of racial categories to include white, black, Hispanic, and other.

Females in our sample serving a longer period of time were also more inclined to engage in consensual homosexual activity than inmates serving a shorter period of time. These women are either deprived of normal "heterosexual outlets" (Sykes, 1958) or "psychological outlets" which may lead to depression and increase their likelihood of participating in homosexual activity.

Religion had a significant impact on only one of the four forms of same-sex sexual behavior. Inmates with a Non-Protestant religious affiliation were more likely than Protestants to perform oral sex on another inmate. However, it is unclear whether religion is an importation factor. Many inmates "find God" while incarcerated and others change their religious preferences once they enter prison. Some of the inmates in our sample indicated that they had no religious affiliation, thereby placing them in the Non-Protestant category. These inmates would probably not be concerned with the religiously-defined ramifications of engaging in same-sex activity. Coding of religion in this study did not capture information about religious fundamentalism, which may also have a discriminatory effect. It is suggested that future studies address- 
ing the religion/homosexuality link examine religious fundamentalism and religious denomination as two separate and discrete variables.

Finally, age is a factor that can be related to both the deprivation and importation models (Greer, 2000; Owen, 1998; Pollock, 1997; Propper, 1981; Nelson, 1974; Heffernan, 1972; Ward and Kassebaum, 1965). Younger inmates (34 years or younger) in our sample were more likely than older inmates (35 years and older) to engage in same-sex sexual behavior. It is possible that because of the increasingly liberal attitudes concerning homosexuality in our society, younger inmates would be more inclined to engage in such behavior (Hopper, 1980). Another possible explanation of the findings suggested by other prison sex researchers (Owen, 1998; Hopper, 1980; Giallombardo, 1966), is that younger inmates engage in same-sex relationships because they are more likely to seek affection and emotional anchors as means to adapt to the realities of prison life. Or perhaps younger women are more sexually active and react more assertively to incarceration by seeking out sexual partners. It also is reasonable to assume that younger women have more experiences with bi or same-sex relationships prior to incarceration and thus they carry these values into the institution. These explanations lend support to both the deprivation and importation models.

In conclusion, both the deprivation and importation models received equal, but limited support in this study. Such essentialist explanations concerning the dichotomy between "fixed" heterosexuality and "static" homosexuality have dominated prison sex research, especially in male correctional facilities (see Eigenberg, 1992). Most research on homosexuality in prison, for example, focuses only on either the behavior or identity of the inmate rather than gauging both the behavior and identity. Nor does the research recognize the "possibility of a changing sexual orientation" (Eigenberg, 2000, p. 418). Thus, as we begin to reject essentialist paradigms of sexuality, we require new paradigms of prison sexuality that do not make bisexuality or "situational" homosexuality a problem to be explained through either the importation or deprivation models.

One such explanation is the social constructionist approach which "concentrates on determining how inmates define and label themselves in terms of their sexuality" (Eigenberg, 1992, p. 230). Social constructionists define a person's sexual orientation based on a continuum which ranges from exclusively heterosexual to exclusively homosexual. Therefore, a person's sexual orientation can change at different times in their lives (Eigenberg, 1992). Most things in life (especially 
prison subcultures) are too complex and require thinking that is able to move beyond the narrow dichotomy of heterosexuality and homosexuality. It is important that future research of female prison sexuality explores this relatively new paradigm.

\section{REFERENCES}

American Psychiatric Association. (1994). Diagnostic and Statistical Manual of Mental Disorders (4th edition). Washington, DC: American Psychiatric Association.

Eigenberg, H. (1992). Homosexuality in male prisons: Demonstrating the need for a social constructionist approach. Criminal Justice Review, 17(2), 219-234.

Eigenberg, H. (2000). Correctional officers and their perceptions of homosexuality, rape, and prostitution in male prisons. The Prison Journal, 80(4), 415-433.

Ford, C. (1929). Homosexual practices of institutionalized females. Journal of Abnormal and Social Psychology, 23, 442-449

Giallombardo, R. (1966). Society of Women: A Study of a Women's Prison. New York: Wiley.

Greer, K. (2000). The changing nature of interpersonal relationships in a women's prison. The Prison Journal, 80(4), 442-468.

Halleck, S. \& Hersko, M. (1962). Homosexual behavior in a correctional institution for adolescent girls. American Journal of Orthopsychiatry, 32, 911-917.

Heffernan, E. (1972). Making it in prison: The square, the cool, and the life. New York: John Wiley and Son, Inc.

Hopper, C. (1980). A Study of Homosexuality and Surrogate Families in an Institution for Women. Master's Thesis, University of South Florida, Tampa.

Irwin, J. \& Cressey, D. (1962). Thieves, convicts, and the inmate culture. Social Problems, 10(Fall), 145-155.

Kassebaum, G. (1972). Sex in prison: Violence, homosexuality, and intimidation are everyday occurrences. Sexual Behavior, 2(1), 39-45.

Nelson, C. (1974). A Study of Homosexuality Among Women Inmates at Two State Prisons. Ph.D. Dissertation, Temple University.

Otis, M. (1913). A perversion not commonly noted. Journal of Abnormal Psychology, $8,113-116$

Owen, B. (1998). "In the Mix," Struggles and Survival in a Women's Prison. Albany, NY: State University of New York Press.

Pollock, J. (1997). Prisons: Today and Tomorrow. Gaithersburg, MD: Aspen Publishers, Inc.

Propper, A. M. (1976). Importation and Deprivation Perspectives on Homosexuality in Correctional Institutions: An Empirical Test of Their Relative Efficacy. Ph.D. Dissertation, University of Michigan, Ann Arbor.

Propper, A. M. (1978). Lesbianism in female and coed correctional institutions. Journal of Homosexuality, 3(3), 265-274.

Propper, A. M. (1981). Prison Homosexuality. Lexington, MA: D.C. Heath and Company. 
Propper, A. M. (1982). Make-believe families and homosexuality among imprisoned girls. Criminology, 20(1), 127-138.

Selling, L. (1931). The pseudo-family. American Journal of Sociology, 37, 247-253.

Sykes, G. (1958). The Society of Captives: A Study of a Maximum Security Prison. Princeton, NJ: Princeton University Press.

Tittle, C. (1972). Society of Subordinates: Inmate Organization in a Narcotic Hospital. Bloomington, IN: Indiana University Press.

Ward, D. \& Kassebaum, G. (1965). Women's Prison: Sex and Social Structure. Chicago, IL: Aldine Publishing Company.

\section{Get Single Articles FAST with the Haworth Electronic Document Delivery Service!}

To request single copies of articles from Haworth

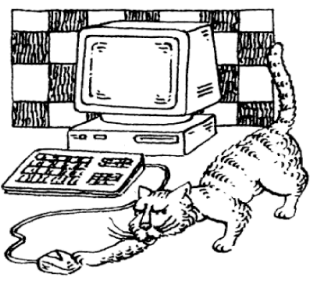
journals at only $\$ 12.00$ each, visit the Haworth website at www. HaworthPress.com today!

Your choice of delivery: EMAIL, FAX, OR REGULAR MAIL! 